Article

\title{
Developmental Trajectories in Electrical Steel Technology Using Patent Information
}

\author{
Donghyun You and Hyunseok Park * \\ Department of Information System, Hanyang University, Seoul 04763, Korea; ryudingdin@gmail.com \\ * Correspondence: hp@hanyang.ac.kr; Tel.: +82-2-2220-2396
}

Received: 20 July 2018; Accepted: 31 July 2018; Published: 2 August 2018

\begin{abstract}
Recently there has been growing demand for low-electricity consuming transformers and electric vehicles due to global trend of reducing use of fossil fuels and the role of electrical steel became important. Tracing and analyzing research trend and development of electrical steel will give insight for development of R\&D direction and strategies. We used patent citation network and GBFP (Genetic Backward-Forward Path analysis) to identify technological trajectories of electrical steel domain and patent contents with other papers to qualitatively analyze research trend of the domain. As a result, we found that some sub-domains of electrical steel domain had close technological relationship to each other in their developmental paths and suggested further R\&D direction in the electrical steel technology.
\end{abstract}

Keywords: electrical steel; classification overlap method; patent citation network; GBFP-based main-path analysis

\section{Introduction}

Electrical steel is soft-magnetic material that has a great magnetic property which is mainly used as material for core of electric devices and machines. Recently there has been growing demand for low-electricity consuming transformers and electric vehicles (EV) due to global trend of reducing use of fossil fuels, and the role of electrical steel became important because it contributes to the improvement in the efficiency of the electric motor of EV [1] and reduction of losses, temperature, energy and costs of transformers [2]. Tracing and analyzing research trend and development of electrical steel will help researchers and $R \& D$ planners better understand the evolving characteristics of electrical steel and it will give insight for development of R\&D direction and strategies.

This paper aims to trace developmental trajectories of electrical steel technology and we used patent citation network to identify them. The patent citation network is used to visualize and identify the technological trajectories in innovation studies [3] and tracing the radical and incremental development process through technological trajectories gives insights into the evolutionary process in a technological domain [3,4]. Patents are reliable knowledge source and widely used for identification of recent trends of high technologies discovery of new technology opportunity and development of technology roadmaps and plans [3-15]. This study used COM (classification overlap method) to collect patent data set. COM is a method to collect patent set that represents a technology domain. It is done by finding IPC (international patent classification) and UPC (united states patent classification) with high frequency from the result of keyword searching. By collecting patents that have the classification found by the keyword searching, data set representing certain technological domain is finalized. The final set has high relevancy and reliability because the method comprehends the patents that could have been lost from the keyword searching, and it is flexible to search terms of researchers $[16,17]$.

We used GBFP (Genetic Backward-Forward Path analysis) based main-path analysis method to analyze citation network. Main-path analysis is widely used to analyze citation network because 
it reduces network complexity and identifies the patents that can realistically represent a specific technological domain, and it contributes to identifying important knowledge trajectory in the citation network. Previous main-path analysis method was used for wide technology area but it itself had some limitations from the theoretical perspective in innovation. It could omit significant patents in technological domain, and it was hard to show multiple trajectories which is an essential factor for explaining technology development by recombination of existing knowledge. However, GBFP based main-path analysis method has such advantages that it reduces complexity of citation network and identifies multiple trajectories with patents of important technologies [8].

\section{Electrical Steel}

Electrical steel sheet is soft-magnetic material which mainly contains iron and 1 4\% of silicon and it is also called as iron-silicon alloy. The beginning of the electrical steel starts with a finding of Hadfield that steel has a great magnetic property when it is alloyed with silicon [18]. Due to its good magnetic property, it is widely used as magnetic core material for wide range of electric machines and devices like power and distribution transformers, induction motors.

Recently there has been growing demand for low-electricity consuming transformers and electric vehicles due to global trend of reducing use of fossil fuels and the role of electrical steel became important because it contributes to the improvement in the efficiency of the electric motor of EV and reduction of losses, temperature, energy and costs of transformers.

The commercial electrical steel sheet can be categorized into grain-oriented and non-oriented electrical steels. They have difference in magnetizing direction in that whereas grain-oriented steel has anisotropic magnetic property to the rolling direction, non-oriented has isotropic magnetic property in all direction. Grain-oriented steel has 'Goss' texture with (110) [100] crystallographic orientation whereas non-oriented steel has 'Cubic' texture with (001) or (110) planes parallel to the plane of the steel and [100] direction uniformly distributed [19].

Due to their magnetization direction grain-oriented steel is mainly used in static machinery which requires unidirectional magnetization, whereas non-oriented steel is mainly used in rotating machinery which requires multidirectional magnetization: Grain-oriented steel is mainly used in transformers and non-oriented steel is used in various devices such as motors, generators and small transformers [1]. Table 1 shows the typical applications of commercial electrical steels [2].

Table 1. Application of commercial electrical steel.

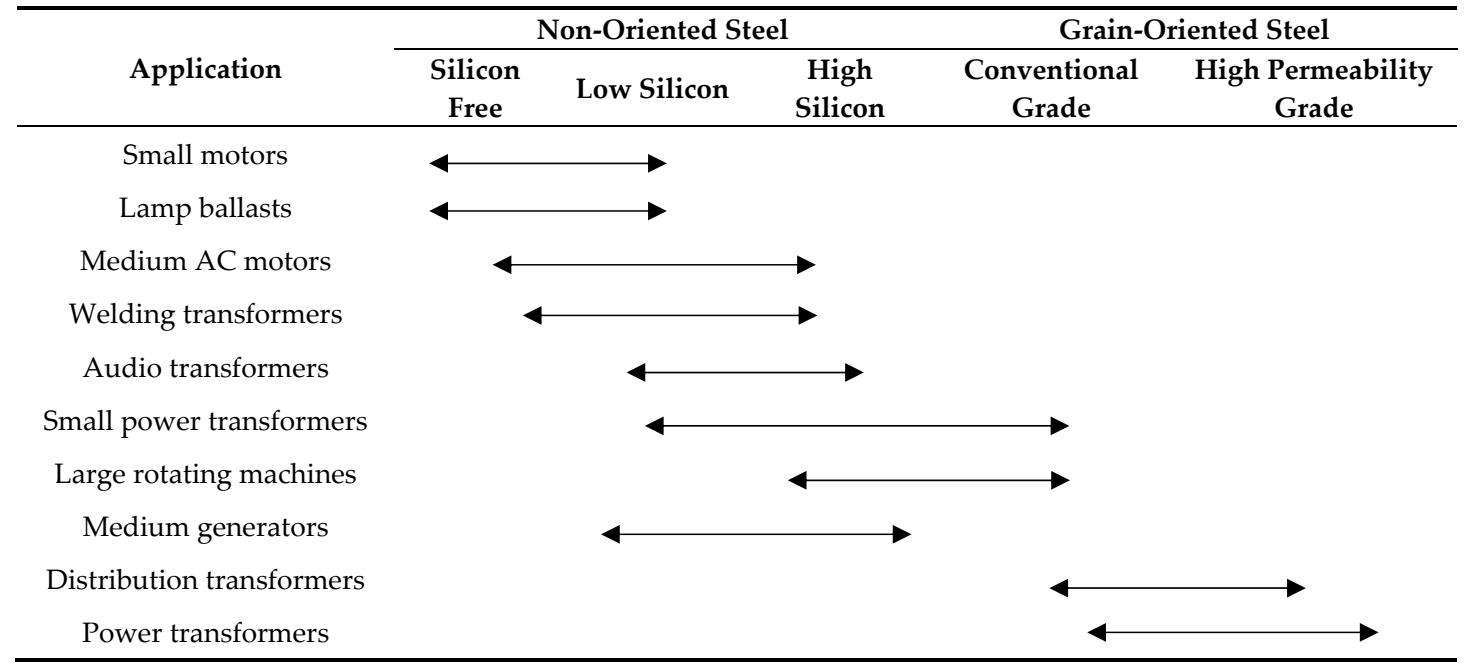

The manufacturing process of electrical steel sheets mainly consists of casting, reheating, hot rolling, cold rolling and final annealing. For example, in the casting stage of the grain-oriented steel 
manufacturing process, various materials are alloyed which determines the future property of the electrical steel: magnetostriction, strength, core loss, permeability and so forth. High temperature reheating stage finely dissolves inhibitor material within alloy. Hot rolling stage contributes to fine precipitation of inhibitor materials in grain-oriented steel which is essential factor for successful secondary recrystallization. The cold rolling stage significantly generates primary recrystallization and reduces the thickness of the steel, which is closely related to the magnetic property of the steel. The decarburization stage follows the cold rolling stage and it reduces carbon content so that the steel does not suffer magnetostriction. In final annealing, some crystals are selectively grown from the primary recrystallized crystal nuclei to texture that has preferred magnetization direction. After the final annealing the electrical steel goes through thermal flattening and punched for assembly of core $[18,19]$.

\section{Data}

Our study used COM to collect patent data set. COM, suggested by [16,17], is a method to collect patent set that represents a technology domain; the definition of technology domain in this paper is 'The set of artifacts that fulfill a specific generic function utilizing a particular, recognizable body of knowledge' [20]. It is conducted by finding IPC (international patent classification) and UPC (united states patent classification) with high frequency from the result of keyword searching. By collecting patents that have the classification found by the approach mentioned above, data set representing certain technological domain is finalized. The final set has high relevancy and reliability because the method comprehends the patents that could have been lost from the keyword searching and is flexible to search terms of researchers $[16,17]$.

We used patent database service Patsnap (www.patsnap.com) to retrieve patent data corresponding to our search query by COM. A search query of electrical steel domain using COM and the number of patents is described in Table 2.

Table 2. Summary of patent set.

\begin{tabular}{cc}
\hline \# of patents & 1681 \\
\hline Period (Application date) & 1 January 1834 31 December 2013 \\
& UPC: $(((148 / 110)$ OR $(148 / 111)$ OR $(148 / 112)$ OR $(148 / 120)$ OR \\
Search query & $(148 / 121)$ OR (148/122) OR (148/306) OR (148/307) OR (148/308) OR \\
& $(148 / 309))$ NOT (420/89)) AND IPC: ((C22C38) OR (H01F1) OR \\
(C21D1) OR (C21D8) OR (C21D9)) NOT (H01f1/2))
\end{tabular}

\section{Method}

\subsection{Citation Network}

The patent citation network is used to visualize and identify the technological trajectories in innovation studies and tracing the radical and incremental development process through technological trajectories gives insights into the evolutionary process in a technological domain. Under the assumption that a patent represents a technology and patent citation represents technological knowledge flow, patent citation network is built where nodes are patents and edges are citation information which indicates knowledge flow from cited to citing documents [8].

\subsection{GBFP Based Main-Path Analysis}

Main-path analysis is widely used to analyze citation network because it reduces network complexity and identifies the patents that can realistically represent a specific technological domain and it contributes to identifying important knowledge trajectory in the citation network. Our study used a Genetic Knowledge Persistence-based Main path approach to identify technological trajectories of electrical steel domain. Previous main-path analysis method was used for wide technology area 
but it itself had some limitations from the theoretical perspective in innovation. It could omit significant patents in technological domain, and it was hard to show multiple trajectories which is an essential factor for explaining technology development by recombination of existing knowledge. GBFP based main-path analysis, suggested by [8], has such advantages that it reduces complexity of citation network and identifies multiple trajectories with important technologies. It comprises of building citation network, measuring genetic knowledge persistence and doing backward and forward searching from HPPs (high persistence patents).

\subsubsection{Genetic Knowledge Persistence and Its Measurement}

Measuring genetic knowledge persistence value of citation network can make improved network environment for identification of technological trajectories and important patents. The Genetic knowledge persistence, suggested by [21], is a concept where the new knowledge is born from the recombination of existing knowledge which follows the Mendelian notion of genetic inheritance. Inheritance in the patent citation network means that parent node (cited patent) inherits knowledge to child node (citing patent). A measuring genetic knowledge persistence is done as followings and Figure 1 explains how knowledge persistence is calculated with an example.

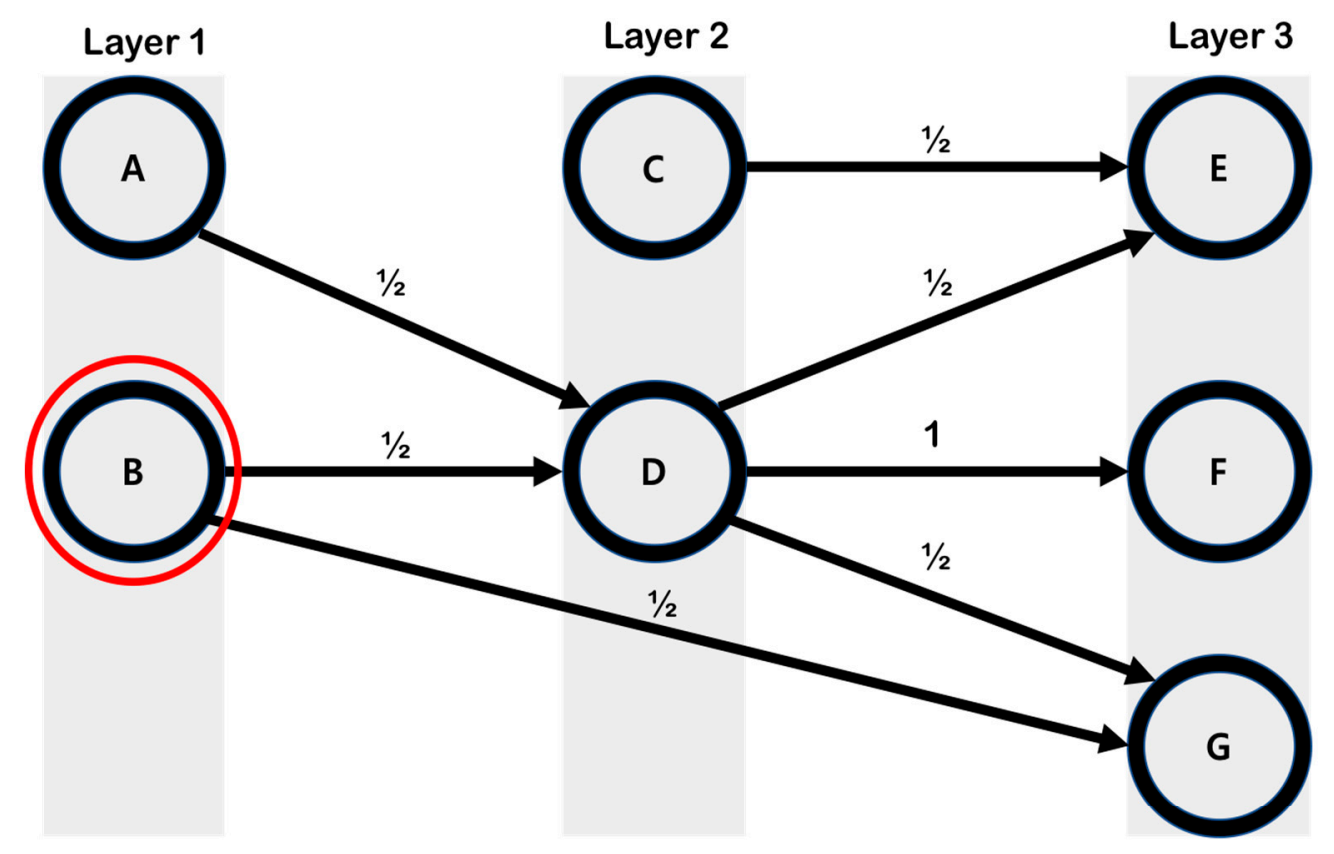

Persistence value of $B$ in layer 3 is sum of descendants $E, F$ and $G$

$$
\begin{array}{ll}
E=1 / 2 * 1 / 2 & B=E+F+G \\
F=1 / 2 & B=1.5 \\
G=1 / 2 * 1 / 2+1 / 2 &
\end{array}
$$

Figure 1. Measurement of knowledge persistence value; Persistence value of $B$ in layer 3 is sum of descendant E, F and G. E has $1 / 2$ of itself as D and D has $1 / 2$ itself as B so $E$ has $1 / 2^{*} 1 / 2$ of itself as knowledge of B. F has entire knowledge as D and D has $1 / 2$ itself as B so F has $1 / 2$ of itself as knowledge of B. G has $1 / 2$ of itself as B and $1 / 2$ of itself as D and D has $1 / 2$ itself as B so $G$ has $1 / 2 * 1 / 2+1 / 2$ knowledge of itself as $B$. The sum of proportion of knowledge B in E, F and G would be the persistence value of $B$ in layer 3 . 
1. Assign patents to layers to draw lineage structure of the network. Patents without in-domain backward citation is assigned to the first layer. In-domain backward citation refers to backward citation among source patent data which is predefined technology domain. Patents citing the patents in the first layer are assigned to the next layer. Patents without in-domain forward citation becomes the end point (end-layer). The maximum length of lineage structure is determined by the longest link in the structure.

2. Measure how much a patent inherited to recently invented patents (end-layer). Value of how much knowledge a parent patent inherited to a child patent in the next layer is calculated by $1 /$ the number of backward citation of a child patent. The knowledge persistence of a patent in entire network is calculate according to the following formula [8]:

$$
K P_{A}=\sum_{i=1}^{n} \sum_{j=1}^{m_{i}} \prod_{k=1}^{l_{j}-1} \frac{1}{B W D C i t\left(P_{i j k}\right)}
$$

where calculation of the knowledge persistence of a patent in entire network; $K P_{A}$ is knowledge persistence value of patent $A\left(P_{A}\right), n$ is the number of patents in the last layer, which are (indirectly) connected to $P_{A}, m_{i}$ is all possible backward paths from $P_{i}$ to $P_{A}, l_{j}$ is the number of patents on the $j$-th backward path from $P_{i}$ to $P_{A}, P_{i j k}$ is the $k$-th patent on the $j$-th backward path from $P_{i}$ to $P_{A}$ and $B W D C i t\left(P_{i j k}\right)$ is the number of backward citations of $P_{i j k}$, without considering backward citations by patents in between the first layer and layer $t-1$, when $P_{A}$ belongs to layer $t$.

\subsubsection{Identification of Main-Paths}

Main paths are identified by GBFP (Genetic Backward-Forward Path) searching from HPPs (high persistence patents) (Appendix A). GP (global persistence) and LP (layer persistence) are needed to define HPP. GP of a patent refers to normalized value where persistence value of a patent is divided by the biggest persistence value in the whole network. LP of a patent refers to normalized value where persistence value of a patent is divided by biggest persistence value in the same layer. HPPs are patents that have GP value up to 0.8 or LP value up to 0.3. GBFP is searching forward and backward through directly connected citing/cited patents selecting a patent that has the biggest GP. Searching ends when it gets to the start or end layer of network. Main paths are identified when GBFP searching is done for every HPP.

\section{Results}

The main paths of electrical steel by proposed method is in Figure 2 drawn by Gephi (www.gephi.org). We used Event graph layout plug-in to arrange patents in layer order and each node is assigned a unique label. Cutoff value of HPP is GP 0.3 and LP 0.8 and there are 78 patents in the main-paths network among which 47 are HPPs.

It is well known fact that electrical steel is mainly used for core material of motor and transformer [3-5]. Based on this fact, we made an assumption that the development of electrical steel aims to fulfill the requirements of electric device core market. Under this assumption we categorized patents on the main-path network into 4 technological sub-domains according to their techniques, effect and value they give to the core of the electrical devices. Formally most electrical steel patents on main-path network describes manufacturing process for producing steel but in claims and description there is a focus that the patent is trying to claim. By qualitatively analyzing patent document on main-path network we categorized them into 4 sub-domains. Figure 2 shows the categorized sub-domains of electrical steel and their trajectories (HPPs are marked with red color, and the sub-domains are shown in Table 3. 


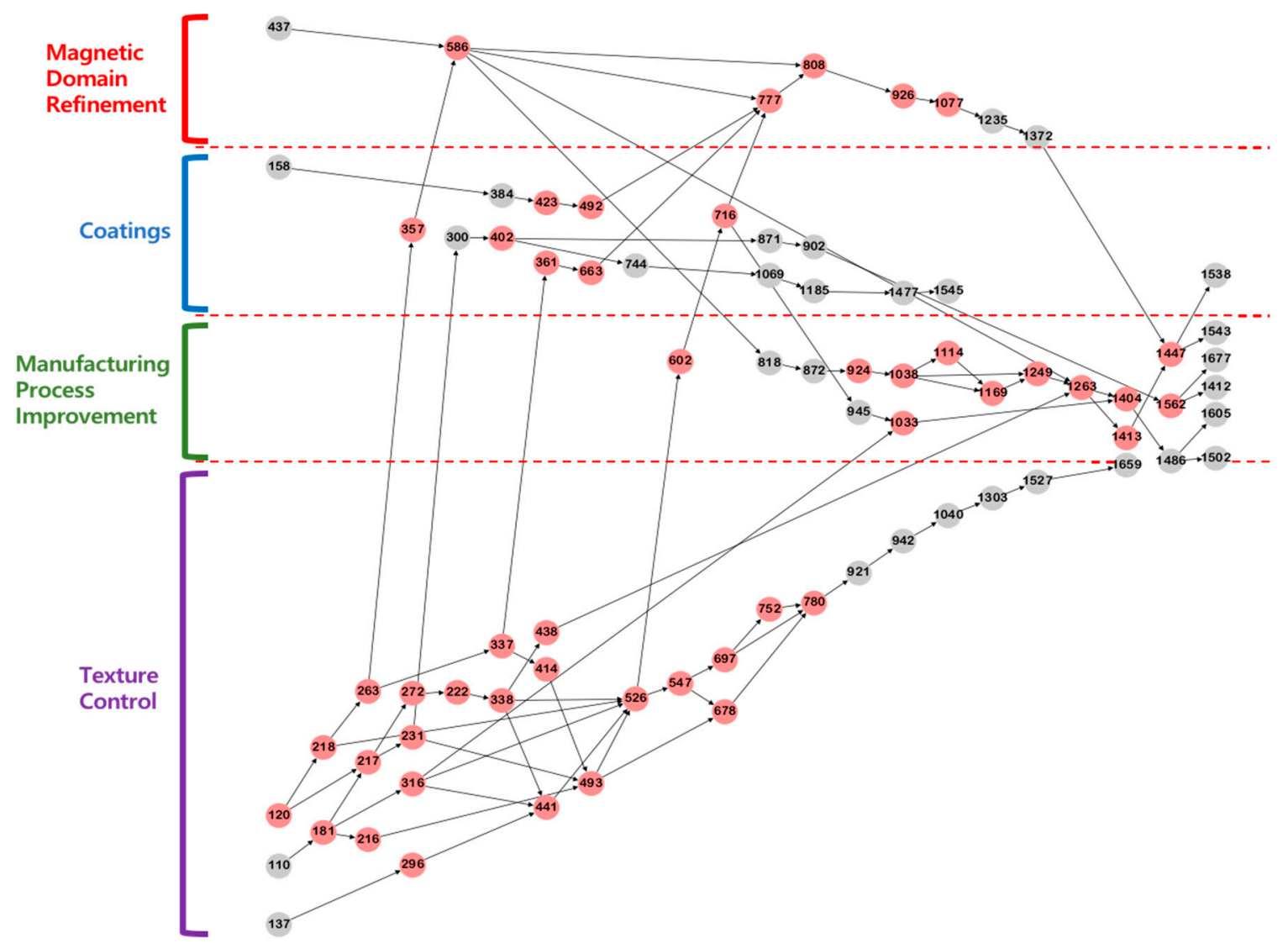

Figure 2. Main path network for Electric steel. Note: There are 4 sub-domains in electrical steel domain: Magnetic domain refinement, Coatings, Manufacturing process improvement and Texture control.

Table 3. Sub-domains of electrical steel, their effect in perspective of electrical steel and value they give to core market. For example, improvement of manufacturing process sub-domain has effect of reducing of manufacturing cost and time in perspective of steel manufacturers and it sequentially makes reduction in cost of electrical steel for core market.

\begin{tabular}{ccc}
\hline Sub-Domain (Techniques) & Major Effect & Value to the Core Market \\
\hline Magnetic domain refinement & Core loss & Performance efficiency \\
Coatings & Core loss & Performance efficiency \\
Improvement of manufacturing process & Reduction of manufacturing cost and time & Low cost \\
Texture control & Core loss and high permeability & Performance efficiency \\
\hline
\end{tabular}

Magnetic domain refinement is a technique of reducing $180^{\circ}$ wall spacing and increasing amounts of $90^{\circ}$ domains to reduce domain-dependent eddy current loss. In 1940 Hayes and Wolford first demonstrated mechanical scratching in perpendicular to the rolling direction of steel that contributed to core lose [22]. This is done after the thermal flattening in the entire manufacturing process. Coating is a technique that contributes to many aspects of manufacturing process of electrical steel. Coating works as annealing separator which prevent laminated stacks of steel from fusion and it is related with good weldability and punchability of steel. But historically major effect of coating would be insulation that reduces eddy-current loss between laminated stacks [18]. Manufacturing process improvement techniques are concerned with development toward lowering manufacturing costs. In the conventional manufacturing process, high temperature slab reheating up to $1400{ }^{\circ} \mathrm{C}$ is essential for fine dissolution of inhibitors which contributes to secondary recrystallization of preferred aggregation texture. But this step generated excess liquid slag which is related with sedimentation in furnace and yield degradation of the material leading to increase in manufacturing cost of steel. Low slab reheating tries to reheat 
slab below $1300{ }^{\circ} \mathrm{C}$ or use alternative methods for dissolving inhibitors as shown in Figure 3 [23]. Texture control aims develop preferred crystal orientation originating from magnetization anisotropy of iron crystal. Preferred crystal orientation contributes to good magnetic permeability and the other magnetic properties. Selectively developing the preferred crystal orientation is called secondary recrystallization and precipitation of inhibitors, hot rolling, cold rolling and final annealing are essential steps for secondary recrystallization [24].

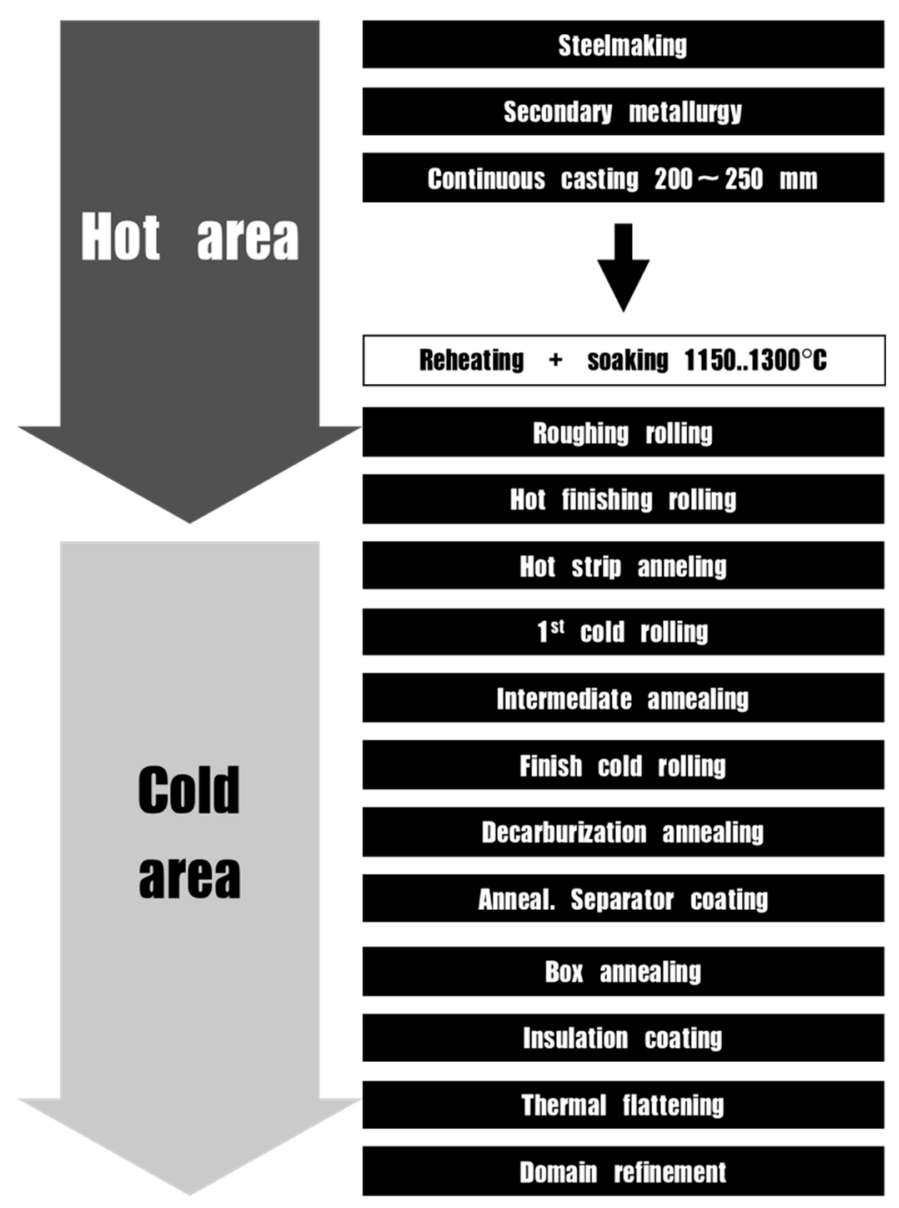

Figure 3. Production schedule with low temperature slab reheating of grain-oriented steel [23].

\section{Developmental Trajectories of Electrical Steel}

Magnetic domain refinement sub-domain shows development path from mechanical scratching to laser beam scribing technique. There were mechanical scratching techniques that contributed to the core loss of the steel in the early period but it caused the problem of insulation degradation and it led to laser scribing technique that has relatively low damage on surface insulation coating [25] which is non-contact technique for reducing core loss [26]. Patent 437586 (US3647575, US3990923) are mechanical scratching techniques. In particular, 437 is assessed as an innovative patent that reduced core loss by $40 \%$ by cutting grooves into surface of the steel [18,22]. Patent 777926 (US4363677, US4909864) are laser beam techniques.

Coating sub-domain shows development path from insulation coating to stress coating. After the finding that stress sensitivity of magnetic power loss can be reduced by coating in the 1970s [27], the development of stress coating started for improvement of magnetic property of electrical steel. Patent 158 (US2385332) is an insulation coating technique using magnesia to get insulation silicate and it is the first to suggest annealing steel in the coil form [28]. Patent 492 (US3856568) is a stress coating 
technique using colloidal silica in the final annealing step which has effect of narrowing and refining magnetic domain of the steel.

Manufacturing process improvement technique sub-domain shows development path from low temperature slab reheating toward reduction of manufacturing process. Patent 10331404 (US5082509, US6432222) are one of the low temperature reheating techniques that uses 'acquired inhibitors.' It nitrides the cold rolled steel in the decarburization step and avoids inhibitor formation in the hot area [22].

Texture control sub-domain shows development path toward controlling aggregation texture using various inhibitor materials. Patent 120,137,181 (US2158065, US2307391, US2599340) are early progresses for obtaining the maximum preferred orientation of 'Goss' texture $[24,28,29]$ but only manganese sulfide is used for inhibitor material because there was no scientific knowledge of the role of inhibitors. After the finding of Dunn in 1949 that secondary recrystallization is responsible for development of preferred texture orientation and May and Turnbull that fine dispersion of inhibitor precipitates is responsible for secondary recrystallization [24], emerged the electrical steels using different material as inhibitors which has high magnetic permeability than the conventional grade. They are called 'high permeability grade' and can be categorized into 3 types as shown in Table 4 [24]. Patents 316 (US3159511) is type 1 that uses aluminum nitride (AIN) as main inhibitors with single cold rolling step [30]. Patent 5471413 (US3940299, US6444051) are type 2 and 3 which use antimony with manganese sulfide and nitride boron as inhibitor respectively.

Table 4. Types of high permeability grade electrical steel.

\begin{tabular}{cccc}
\hline \multirow{2}{*}{ Conventional Grades } & \multicolumn{3}{c}{ High Permeability Grades } \\
\cline { 2 - 4 } & Type No.1 & Type No. 2 & Type No. 3 \\
\hline Steelmaking & Steelmaking & Steelmaking & Steelmaking \\
Microalloy $($ MnS $)$ & Microalloy (AlN + MnS) & Microalloy (MnS + Sb, Mo) & Microalloy (B + N + S or Se) \\
Hot rolling & Hot rolling & Hot rolling & Hot rolling \\
Reheating $(1593 \mathrm{~K})$ & Reheating $(1633 \mathrm{~K})$ & Reheating $(1593 \mathrm{~K})$ & Reheating $(1523 \mathrm{~K})$ \\
Annealing $(1073 \sim 1273 \mathrm{~K})$ & Annealing $(1373 \mathrm{~K})$ & Annealing $(1173 \mathrm{~K})$ & Annealing $(1148 \sim 1298 \mathrm{~K})$ \\
Cold rolling $(70 \%)$ & Cold rolling $(87 \%)$ & Cold rolling & Cold rolling $(80 \%)$ \\
Annealing $(1073 \sim 1273 \mathrm{~K})$ & & Annealing & \\
Cold rolling $(55 \%)$ & Cold rolling $(65 \%)$ & Decarburizing \\
Decarburizing $\left(1073 \mathrm{~K}\right.$, wet $\left.\mathrm{H}_{2}+\mathrm{N}_{2}\right)$ & Decarburizing & Decarburizing & Box annealing $(1093 \sim 1173 \mathrm{~K}$, \\
Box annealing $\left(1473 \mathrm{~K}\right.$, dry $\left.\mathrm{H}_{2}\right)$ & Box annealing $(1473 \mathrm{~K})$ & Box annealing $(1473 \mathrm{~K})$ \\
\hline
\end{tabular}

In addition, there are patents like Patent 14861502 (US6893510, US7198682) that are located where boundaries of texture control and manufacturing process improvement subdomain face each other. The patents produce electrical steel using thin strip casting technology where the hot strip in the thickness of about $2 \sim 3 \mathrm{~mm}$ is produced by direct casting from the steel melt. It has remarkable process shortening as shown in Figure 4 which contributes to reduction of manufacturing cost and it uses unconventional method of precipitating inhibitors induced by rapid cooling of the cast strip [23]. Patent 1486 is assessed as new concept of strip casting using the both 'inherent' and 'acquired' inhibitors which is expected to give a more stable texture [23]. 


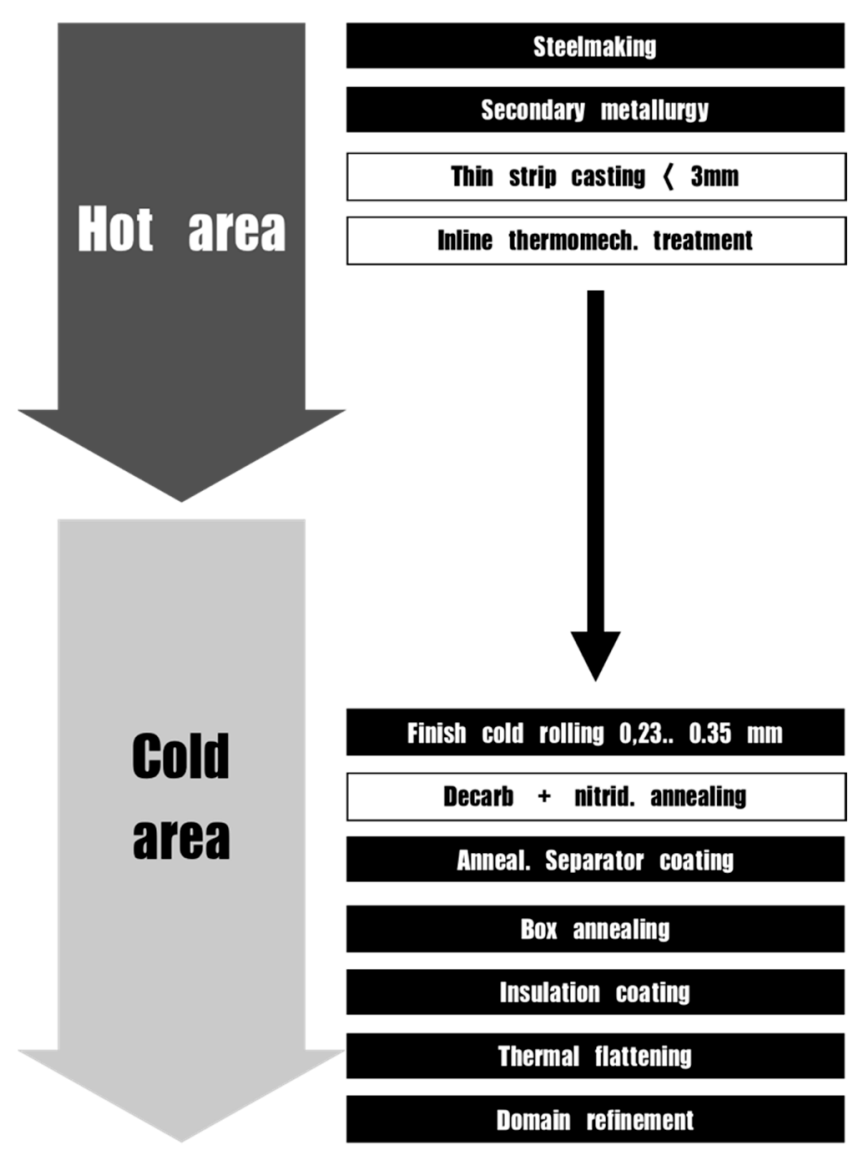

Figure 4. Maximum process shortening in the hot area by direct casting to less than $3 \mathrm{~mm}$ [23].

\section{Conclusions}

In this study, we used citation network and GBFP approach to identify developmental trajectories of electrical steel, and we categorized the trajectories into four sub-domains from the perspective of core of electric devices and machines. The sub-domains showed close relationships to each other in their development paths. Insulation technique in the coating sub-domain has improved core loss of the steel by giving insulation film between laminated stacks but mechanical scratching technique in magnetic domain refinement sub-domain damaged the film resulting increased eddy-current loss between laminated stacks. To solve this problem, laser scribing technique is invented. Additionally, controlling texture using inhibitors could provide improved magnetic permeability for steel but high temperature slab reheating stage in conventional manufacturing process to finely dissolve inhibitors generated sediment of furnace and degradation of material yield. To solve this problem low slab reheating techniques avoiding inhibitor formation in the hot area of manufacturing process is invented which could protect manufacturing environment from excess slag and increase of manufacturing cost.

Based on the characteristics of electrical steel patents and developmental path shown on main-path network, we suggest further R\&D direction as followings. In sub-domain of magnetic domain refinement, the further $R \& D$ direction is likely to be toward solving increase in iron loss of materials having a high alignment of grain orientations. According to HPP 1372 (US6444050), the materials have large grain diameter makes large distance between grain boundaries and magnetostatic energy generation is weakened which means that domain refined area is reduced and magnetic domain is enlarged followed by increase in iron loss.

In sub-domain of coatings, the further R\&D direction is likely to focus on find alternative coating material of forsterite that can provide the same function and has relatively low damage on punching die, or develop manufacturing method that does not require undercoating. According to a HPP 1538 
(US7371291), forsterite $\left(\mathrm{MgSiO}_{4}\right)$ undercoating which is used for insulation and tension application has problem of deteriorating punching die. Punching die is used to punch a steel sheet and make final shape for assembly of core but forsterite undercoating is extremely hard to punch that the punching die must be early re-polished or exchanged eventually causing damage in working efficiency of core processing by a user and an increase in cost.

Thin strip casting technology HPPs like 1486, 1502 (US6893510, US7198682) which lie in the boundaries of two sub-domains (manufacturing process improvement, texture control) would influence the further R\&D direction of texture control and manufacturing process improvement sub-domains. In sub-domain of manufacturing process improvement, it is likely to focus on manufacturing process including process shortening techniques. For example, thin strip casting technology like HPP 1486 eliminates the thick slab casting and reduce hot rolling passes by supplying as-cast with thickness close to the conventional hot rolled sheets which can reduce the total stages in the manufacturing process and it can be economical way of producing electrical steel. The sub-domain of texture control is likely to be effected by development of process shortening techniques because process shortening technique like thin strip casting omits hot rolling stage, and without hot rolling stage fine precipitation of inhibitor materials and secondary recrystallization is deteriorated in conventional steel making process. Like using 'acquired' inhibitors, texture control sub-domain is likely to focus on finding alternative way of forming inhibitors to control secondary recrystallization.

Author Contributions: Conception and design: H.P. Literature review: D.Y. Data collection and analysis: D.Y. Manuscript writing: all authors. Final approval of the manuscript: all authors.

Funding: Hanyang University (Grant number: HY-2016).

Acknowledgments: This research was supported by Hanyang University (Grant number: HY-2016).

Conflicts of Interest: The authors declare no conflict of interest. 


\section{Appendix A. List of High Persistence Patents in the Electric Steel Technology}

\begin{tabular}{|c|c|c|c|c|c|c|c|c|}
\hline $\begin{array}{l}\text { Patent } \\
\text { Number }\end{array}$ & $\begin{array}{l}\text { Serial } \\
\text { Number }\end{array}$ & Layer & $\begin{array}{l}\text { Application } \\
\text { Year }\end{array}$ & Persistence & GP & LP & $\begin{array}{l}\text { Number of In-Domain } \\
\text { Forward Citations }\end{array}$ & Title \\
\hline US2158065 & 120 & 1 & 1935 & 13.5349 & 0.26566 & 1 & 12 & Art of producing magnetic materials \\
\hline US2599340 & 181 & 2 & 1948 & 50.9471 & 1 & 1 & 25 & Process of increasing the permeability of oriented silicon steels \\
\hline US2867557 & 216 & 3 & 1956 & 24.4019 & 0.47897 & 0.64265 & 20 & Method of producing silicon steel strip \\
\hline US2867559 & 217 & 3 & 1956 & 37.9708 & 0.7453 & 1 & 14 & Method for producing grain oriented silicon steel \\
\hline US2867558 & 218 & 2 & 1956 & 22.082 & 0.43343 & 0.43343 & 19 & Method for producing grain-oriented silicon steel \\
\hline US3164496 & 222 & 5 & 1956 & 40.1215 & 0.78751 & 1 & 7 & Magnetic material and method of fabrication \\
\hline US2992952 & 231 & 4 & 1957 & 31.5646 & 0.61956 & 1 & 17 & Method of manufacturing magnetic sheets \\
\hline US3090711 & 263 & 3 & 1959 & 16.877 & 0.33126 & 0.44447 & 11 & Procedure for secondary recrystallization \\
\hline US2992951 & 272 & 4 & 1960 & 23.1021 & 0.45345 & 0.7319 & 11 & Iron-silicon magnetic sheets \\
\hline US3151005 & 296 & 4 & 1961 & 15.7386 & 0.30892 & 0.49862 & 9 & Method of producing grain-oriented electrical steel \\
\hline US3159511 & 316 & 4 & 1962 & 18.8119 & 0.36924 & 0.59598 & 19 & Process of producing single-oriented silicon steel \\
\hline US3212942 & 337 & 6 & 1963 & 17.4406 & 0.34233 & 0.37347 & 8 & Process for producing double-oriented magnetic steel sheets \\
\hline US3266955 & 338 & 6 & 1963 & 46.6992 & 0.91662 & 1 & 8 & $\begin{array}{l}\text { Process for producing silicon steel sheet having (100) plane in the } \\
\text { rolling plane }\end{array}$ \\
\hline US3347718 & 357 & 4 & 1964 & 16.1724 & 0.31743 & 0.51236 & 17 & Method for improving the magnetic properties of ferrous sheets \\
\hline US3379581 & 361 & 7 & 1964 & 17.6283 & 0.34601 & 0.55203 & 7 & Desulfurizing coating for ferrous material and method of using it \\
\hline US3522108 & 402 & 6 & 1967 & 20.8321 & 0.4089 & 0.44609 & 7 & $\begin{array}{l}\text { Method of forming electric insulating films on al - containing silicon } \\
\text { steel sheet and surface-coated al-containing silicon steel sheet }\end{array}$ \\
\hline US3513039 & 414 & 7 & 1967 & 21.7535 & 0.42698 & 0.68121 & 1 & Process for reduction of core losses in cube textured iron-silicon alloys \\
\hline US3533861 & 423 & 7 & 1968 & 20.0484 & 0.39351 & 0.62781 & 2 & $\begin{array}{l}\text { Method of improving the magnetostriction and core loss of } \\
\text { cube-on-face oriented magnetic steels }\end{array}$ \\
\hline US3636579 & 438 & 7 & 1969 & 19.9658 & 0.39189 & 0.62523 & 20 & $\begin{array}{l}\text { Process for heat-treating electromagnetic steel sheets having a high } \\
\text { magnetic induction }\end{array}$ \\
\hline US3632456 & 441 & 7 & 1969 & 31.9337 & 0.6268 & 1 & 21 & $\begin{array}{l}\text { Method for producing an electromagnetic steel sheet of a thin sheet } \\
\text { thickness having a high-magnetic induction }\end{array}$ \\
\hline US3856568 & 492 & 8 & 1972 & 16.2183 & 0.31834 & 0.43967 & 13 & $\begin{array}{c}\text { Method for forming an insulating film on an oriented silicon } \\
\text { steel sheet }\end{array}$ \\
\hline
\end{tabular}




\begin{tabular}{|c|c|c|c|c|c|c|c|c|}
\hline $\begin{array}{c}\text { Patent } \\
\text { Number }\end{array}$ & $\begin{array}{l}\text { Serial } \\
\text { Number }\end{array}$ & Layer & $\begin{array}{l}\text { Application } \\
\quad \text { Year }\end{array}$ & Persistence & GP & LP & $\begin{array}{l}\text { Number of In-Domain } \\
\text { Forward Citations }\end{array}$ & Title \\
\hline US3770517 & 493 & 8 & 1972 & 36.8871 & 0.72403 & 1 & 25 & $\begin{array}{l}\text { Method of producing substantially non-oriented silicon steel strip by } \\
\text { three-stage cold rolling }\end{array}$ \\
\hline US3940299 & 547 & 10 & 1974 & 27.2568 & 0.535 & 0.84523 & 21 & $\begin{array}{c}\text { Method for producing single-oriented electrical steel sheets having a } \\
\text { high magnetic induction }\end{array}$ \\
\hline US3990923 & 586 & 5 & 1975 & 18.5269 & 0.36365 & 0.46177 & 41 & Method of producing grain oriented electromagnetic steel sheet \\
\hline US4130447 & 663 & 8 & 1977 & 16.5953 & 0.32574 & 0.44989 & 5 & Annealing separator and steel sheet coated with same \\
\hline US4204890 & 678 & 11 & 1978 & 19.6149 & 0.38501 & 0.59897 & 28 & $\begin{array}{l}\text { Method of producing non-oriented silicon steel sheets having an } \\
\text { excellent electromagnetic property }\end{array}$ \\
\hline US4174235 & 697 & 11 & 1978 & 15.3057 & 0.30042 & 0.46738 & 4 & $\begin{array}{c}\text { Product and method of producing silicon-iron sheet material } \\
\text { employing antimony }\end{array}$ \\
\hline US4242155 & 716 & 11 & 1979 & 32.7477 & 0.64278 & 1 & 4 & $\begin{array}{l}\text { Method of forming an insulating film on a grain-oriented silicon } \\
\text { steel sheet }\end{array}$ \\
\hline US4280856 & 752 & 12 & 1980 & 17.1455 & 0.33654 & 0.56741 & 6 & $\begin{array}{l}\text { Method for producing grain-oriented silicon steel sheets having a very } \\
\text { high magnetic induction and a low iron loss }\end{array}$ \\
\hline US4363677 & 777 & 12 & 1981 & 30.217 & 0.59311 & 1 & 18 & $\begin{array}{l}\text { Method for treating an electromagnetic steel sheet and an } \\
\text { electromagnetic steel sheet having marks of laser-beam irradiation on } \\
\text { its surface }\end{array}$ \\
\hline US4421574 & 780 & 13 & 1981 & 10.2212 & 0.20062 & 0.89756 & 8 & $\begin{array}{l}\text { Method for suppressing internal oxidation in steel with } \\
\text { antimony addition }\end{array}$ \\
\hline US4554029 & 808 & 13 & 1982 & 11.3878 & 0.22352 & 1 & 11 & Local heat treatment of electrical steel \\
\hline US4773948 & 924 & 14 & 1987 & 13.1473 & 0.25806 & 1 & 7 & $\begin{array}{l}\text { Method of producing silicon iron sheet having excellent soft } \\
\text { magnetic properties }\end{array}$ \\
\hline US4909864 & 926 & 15 & 1987 & 8.6317 & 0.16942 & 0.84359 & 3 & $\begin{array}{l}\text { Method of producing extra-low iron loss grain oriented silicon } \\
\text { steel sheets }\end{array}$ \\
\hline US5082509 & 1033 & 15 & 1990 & 10.232 & 0.20084 & 1 & 8 & $\begin{array}{l}\text { Method of producing oriented electrical steel sheet having superior } \\
\text { magnetic properties }\end{array}$ \\
\hline US5039359 & 1038 & 15 & 1990 & 9.7086 & 0.19056 & 0.94885 & 6 & $\begin{array}{l}\text { Process for producing grain-oriented electrical steel sheet having } \\
\text { superior magnetic characteristic }\end{array}$ \\
\hline
\end{tabular}




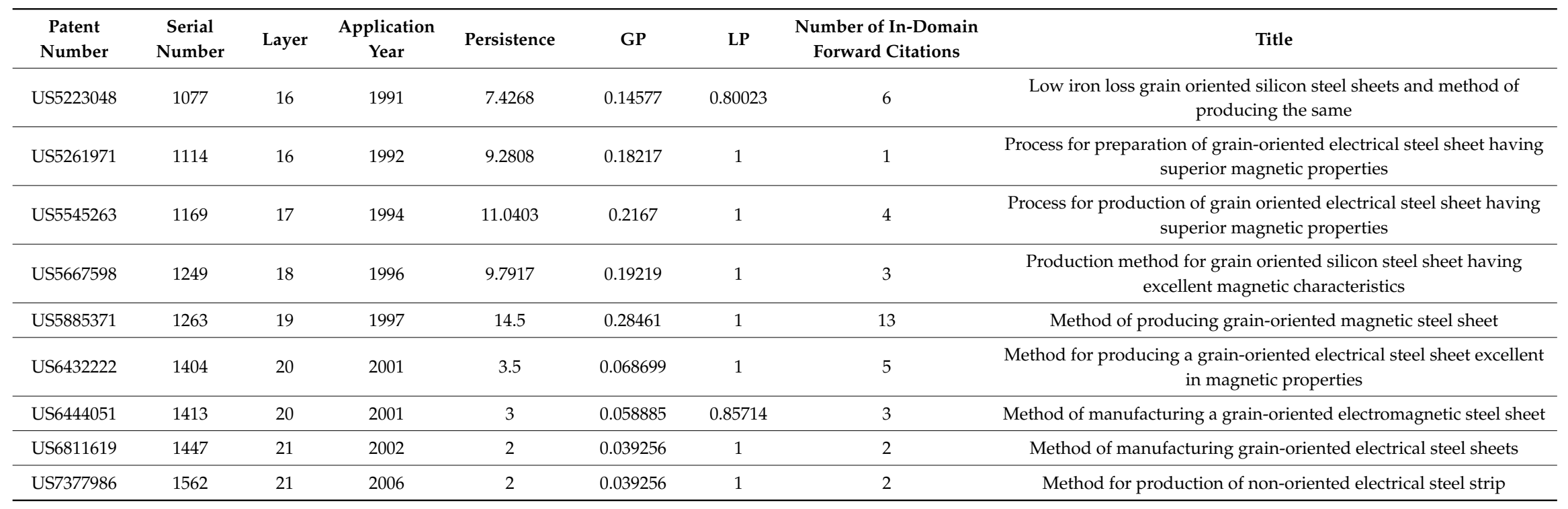




\section{References}

1. Oda, Y.; Kohno, M.; Honda, A. Recent development of non-oriented electrical steel sheet for automobile electrical devices. J. Magn. Magn. Mater. 2008, 320, 2430-2435. [CrossRef]

2. Magdaleno-Adame, S.; Kefalas, T.D.; Garcia-Martinez, S.; Perez-Rojas, C. Electromagnetic Finite Element Analysis of Electrical Steels Combinations in Lamination Core Steps of Single-phase Distribution Transformers. In Proceedings of the 2017 IEEE International Autumn Meeting on Power, Electronics and Computing (ROPEC), Ixtapa, Mexico, 8-10 November 2017; pp. 1-5.

3. Verspagen, B. Mapping technological trajectories as patent citation networks: A study on the history of fuel cell research. Adv. Complex Syst. 2007, 10, 93-115. [CrossRef]

4. Martinelli, A. An emerging paradigm or just another trajectory? Understanding the nature of technological changes using engineering heuristics in the telecommunications switching industry. Res. Policy 2012, 41, 414-429. [CrossRef]

5. Park, H.; Ree, J.J.; Kim, K. Identification of promising patents for technology transfers using TRIZ evolution trends. Expert Syst. Appl. 2013, 40, 736-743. [CrossRef]

6. Jaffe, A.B.; Trajtenberg, M. Patents, Citations, and Innovations: A Window on the Knowledge Economy; MIT Press: Cambrideg, MA, USA, 2002.

7. Choi, S.; Park, H. Investigation of strategic changes using patent co-inventor network analysis: The case of samsung electronics. Sustainability 2016, 8, 1315. [CrossRef]

8. Park, H.; Magee, C.L. Tracing technological development trajectories: A genetic knowledge persistence-based main path approach. PLoS ONE 2017, 12, e0170895. [CrossRef] [PubMed]

9. Shih, M.-J.; Liu, D.-R.; Hsu, M.-L. Discovering competitive intelligence by mining changes in patent trends. Expert Syst. Appl. 2010, 37, 2882-2890. [CrossRef]

10. Wang, G.; Guan, J. Measuring science-technology interactions using patent citations and author-inventor links: An exploration analysis from Chinese nanotechnology. J. Nanopart. Res. 2011, 13, 6245-6262. [CrossRef]

11. Fleming, L. Recombinant uncertainty in technological search. Manag. Sci. 2001, 47, 117-132. [CrossRef]

12. Fleming, L.; Sorenson, O. Technology as a complex adaptive system: Evidence from patent data. Res. Policy 2001, 30, 1019-1039. [CrossRef]

13. Benson, C.L.; Magee, C.L. Quantitative determination of technological improvement from patent data. PLoS ONE 2015, 10, e0121635. [CrossRef] [PubMed]

14. Yoon, J.; Kim, K. Identifying rapidly evolving technological trends for R\&D planning using SAO-based semantic patent networks. Scientometrics 2011, 88, 213-228.

15. Choi, S.; Park, H.; Kang, D.; Lee, J.Y.; Kim, K. An SAO-based text mining approach to building a technology tree for technology planning. Expert Syst. Appl. 2012, 39, 11443-11455. [CrossRef]

16. Benson, C.L.; Magee, C.L. A hybrid keyword and patent class methodology for selecting relevant sets of patents for a technological field. Scientometrics 2013, 96, 69-82. [CrossRef]

17. Benson, C.L.; Magee, C.L. Technology structural implications from the extension of a patent search method. Scientometrics 2015, 102, 1965-1985. [CrossRef]

18. Moses, A. Electrical steels: Past, present and future developments. Phys. Sci. Meas. Instrum. Manag. Educ. 1990, 137, 233-245. [CrossRef]

19. Petrovic, D.S. Non-oriented electrical steel sheets. Mater. Tehnol. 2010, 44, 317-325.

20. Magee, C.; Basnet, S.; Funk, J.; Benson, C. Quantitative empirical trends in technical performance. Technol. Forecast. Soc. Chang. 2016, 104, 237-246. [CrossRef]

21. Martinelli, A.; Nomaler, Ö. Measuring knowledge persistence: A genetic approach to patent citation networks. J. Evol. Econ. 2014, 24, 623-652. [CrossRef]

22. Xia, Z.; Kang, Y.; Wang, Q. Developments in the production of grain-oriented electrical steel. J. Magn. Magn. Mater. 2008, 320, 3229-3233. [CrossRef]

23. Günther, K.; Abbruzzese, G.; Fortunati, S.; Ligi, G. Recent Technology Developments in the Production of Grain-Oriented Electrical Steel. Steel Res. Int. 2005, 76, 413-421. [CrossRef]

24. Matsuo, M. Texture control in the production of grain oriented silicon steels. ISIJ Int. 1989, $29,809-827$. [CrossRef]

25. Siebert, R.; Schneider, J.; Beyer, E. Laser cutting and mechanical cutting of electrical steels and its effect on the magnetic properties. IEEE Trans. Magn. 2014, 50, 1-4. [CrossRef] 
26. Iuchi, T.; Yamaguchi, S.; Ichiyama, T.; Nakamura, M.; Ishimoto, T.; Kuroki, K. Laser processing for reducing core loss of grain oriented silicon steel. J. Appl. Phys. 1982, 53, 2410-2412. [CrossRef]

27. Washko, S.; Choby, E. Evidence for the effectiveness of stress coatings in improving the magnetic properties of high permeability 3\% Si-Fe. IEEE Trans. Magn. 1979, 15, 1586-1591. [CrossRef]

28. Littmann, M. Iron and silicon-iron alloys. IEEE Trans. Magn. 1971, 7, 48-60. [CrossRef]

29. Cole, G. Grain-oriented iron-silicon alloys. Electr. Eng. 1953, 72, 411-416. [CrossRef]

30. Kubota, T. Recent Progress on Non-oriented Silicon Steel. Steel Res. Int. 2005, 76, 464-470. [CrossRef]

(C) 2018 by the authors. Licensee MDPI, Basel, Switzerland. This article is an open access article distributed under the terms and conditions of the Creative Commons Attribution (CC BY) license (http:/ / creativecommons.org/licenses/by/4.0/). 